\title{
DENSIDADE DE SEMEADURA E REGULADOR DE CRESCIMENTO NO ARROZ DE TERRAS ALTAS
}

Renato Jaqueto Goes ${ }^{1}$, Ricardo Antonio Ferreira Rodrigues ${ }^{2}$, Orivaldo Arf $^{3}$, Anderson Teruo Takasu ${ }^{4}$, Rafael Gonçalves Vilela ${ }^{5}$, João Paulo Ferreira ${ }^{4}$, Renata da Silva Moura ${ }^{4}$

${ }^{1}$ Discente do Programa de Pós-Graduação em Agronomia, FEIS / UNESP Campus de Ilha Solteira, SP.

${ }^{2}$ Prof $^{\mathrm{o}}$ Dr. do Departamento de Fitossanidade Engenharia Rural e Solos, FEIS / UNESP Campus de Ilha Solteira, SP.

${ }^{3}$ Docente do Departamento de Fitotecnia, Tecnologia de Alimentos e Sócio Economia, FEIS / UNESP Campus de Ilha Solteira, SP.

${ }^{4}$ Discente do Programa de Pós-Graduação em Agronomia, FEIS / UNESP Campus de Ilha Solteira, SP.

${ }^{5}$ Discente do Programa de Pós-Graduação em Produção Vegetal, UFMS - CPCS, Chapadão do Sul, MS.

RESUMO: O objetivo deste experimento foi verificar o efeito de densidades de semeadura e regulador de crescimento em algumas características agronômicas e na produtividade da cultura do arroz em Selvíria (MS) durante duas safras consecutivas, 2010/11 e 2011/12. O delineamento experimental utilizado foi o de blocos ao acaso, no esquema de parcelas subdivididas com quatro repetições. Os tratamentos consistiram em nove densidades de semeadura $\left(60,90,120,150,180,210,240,270\right.$ e 300 sementes viáveis $\left.\mathrm{m}^{-2}\right)$ combinadas com e sem o uso do regulador vegetal. O uso do regulador de crescimento etil-trinexapac reduz a altura e o acamamento das plantas. $\mathrm{O}$ aumento da densidade de semeadura reduz a produtividade de grãos quando o arroz é cultivado em local que anteriormente fora cultivada leguminosas. A produtividade do arroz é aumentada pelo uso do regulador devido à redução do número de espiguetas chochas, aumento da massa de cem grãos, redução do acamamento e da altura de plantas o que reduz as perdas de grãos na colheita.

Palavras-chave: Oryza sativa cv. Primavera. Acamamento. População de plantas.

\section{SOWING DENSITIES AND GROWTH REGULATOR IN UPLAND RICE CROP}

\begin{abstract}
The objective of this experiment was to verify sowing densities and growth regulator effect in some rice agronomic characters and yield at Selvíria (MS) along two consecutive crops years 2010/11 e 2011/12. Experimental design was randomized blocks in split-splot scheme with four replications. Treatments consisted in combination among nine sowing densities $\left(60,90,120,150,180,210,240,270\right.$ and 300 able seeds $\left.\mathrm{m}^{-2}\right)$ with and without growth regulator use. The use of growth regulator ethil-trinexpac reduce plants height and lodging. The increase of sowing densities decrease the grains yield when rice is cropped in a place that therebefore was cropped with legumes. The rice grains yield is increased by the regulator use because of empty spikelets decrease, increase of one hundred grains weight, reduction of lodging and plants height that decrease the grains losses at harvest.
\end{abstract}

Key words: Oryza sativa cv. Primavera. Lodging. Plant population.

Cultura Agronômica, Ilha Solteira, v.24, n.2, p.119-134, 2015 


\section{INTRODUÇÃO}

O arroz possui grande importância na alimentação básica da população brasileira por ser fonte de calorias e de proteínas. Segundo dados da Conab (2012), a área cultivada com arroz na safra 2011/12 foi de 2.454,7 mil hectares, 13\% menor que a área da safra anterior e na regiões Centro-Oeste e Sudeste, onde predomina-se o cultivo do arroz de terras altas, o Mato Grosso do Sul foi o Estado com a maior produtividade $\left(6.420 \mathrm{~kg} \mathrm{ha}^{-1}\right)$. Ainda existem muitos desafios da pesquisa brasileira para a solução de problemas referentes ao cultivo nesta região. Isto se deve principalmente ao fato que a produtividade nestas condições depende da interação de vários componentes de produção como a fertilidade de espiguetas, o número de espiguetas férteis por panícula e o perfilhamento útil que são influenciados pelas características genéticas dos cultivares e pelos fatores ambientais a que estes serão submetidos durante seu ciclo como a densidade de semeadura, a adubação, o manejo de solo e a irrigação (CRUSCIOL et al., 2007; CAZETTA et al., 2008).

Nos últimos anos, a pesquisa vem desenvolvendo cultivares com maior potencial produtivo, principalmente aqueles que possuem os grãos do tipo agulhinha, implicando no maior uso de insumos, principalmente os fertilizantes nitrogenados. No entanto, a utilização de doses cada vez mais elevadas deste nutriente, para aumentar a produtividade, acarreta muitas vezes em elevado desenvolvimento vegetativo, o que pode resultar em acamamento de plantas e interferir negativamente na produtividade e na qualidade dos grãos (BUZETTI et al., 2006).

Uma possibilidade de reduzir o acamamento é o uso de reguladores de crescimento. Os reguladores vegetais são compostos sintéticos aplicados sobre as plantas, para obtenção de diversos efeitos, tais como o de promover, retardar ou inibir o crescimento vegetativo, sem diminuição na produtividade (BIASI, 2002). O etil-trinexapac é um regulador com forte ação na inibição da elongação dos entrenós, o que reduz a estatura da planta e evita, dessa forma, o acamamento e perdas na produtividade associadas a esse fenômeno (HECKMAN et al. 2002; TAIZ e ZEIGER, 2009).

O momento e os modos de aplicação do regulador de crescimento têm sido alvo de pesquisa, pois seus efeitos sobre a produção demonstram-se inconsistentes, verificando-se aumento de produtividade em alguns casos e, em outros, diminuição (BUZETTI et al., 2006). Em trabalho conduzido no município de Selvíria (MS), Nascimento (2008) verificou que a aplicação de etil-trinexapac no cultivar Primavera reduziu a altura das plantas de arroz em $0,40 \mathrm{~m}$ na dose de $150 \mathrm{~g} \mathrm{ha}^{-1}$ do i.a. quando aplicado por ocasião diferenciação floral e não reduziu a produtividade do arroz. Contudo, Silva (2009) estudando o mesmo cultivar nesta região observou que a aplicação de $150 \mathrm{~g}$ do i.a. ha ${ }^{-1}$ de etil-trinexapac na diferenciação floral resultou em plantas com menor altura e acamamento, entretanto, com redução na produtividade de grãos.

Além do regulador de crescimento, para alcançar altas produtividades torna-se necessário a adequação da densidade de semeadura para proporcionar melhor exploração dos recursos naturais como água, fertilizantes e luz. Silva et al. (2006), mencionam que o 
espaçamento entrelinhas e a densidade de plantas, são práticas de manejo que se destacam para otimizar a produtividade de grãos de arroz, pois afetam a interceptação da radiação fotossinteticamente ativa, um dos principais determinantes da produtividade.

As combinações ótimas entre espaçamento e densidade são muito variáveis, pois são muitos os fatores que interagem com a planta e permitem a máxima expressão gênica do cultivar (CARVALHO et al., 2008). Silva (2009), em pesquisa sobre densidades aliado ao uso do etil-trinexapac e regulador de crescimento, verificou que a maior produtividade foi obtida com o uso de aproximadamente 150 sementes viáveis $\mathrm{m}^{-2}$. Soares (2005) mencionou que para o arroz de terras altas pode-se recomendar espaçamentos de 0,40 a 0,50m entrelinhas com densidade de semeadura entre 60 a 70 sementes $\mathrm{m}^{-2}$. Em pesquisa conduzida em Santo Antônio de Goiás, a produtividade do cultivar BRS Primavera foi maximizada com a adoção de 80-100 sementes por metro quadrado, no espaçamento de 0,30-0,40 m entrelinhas (GUIMARÃES; STONE, 2004).

Diante do exposto, o presente trabalho teve como objetivo verificar as características agronômicas da cultura do arroz, cv. Primavera, sob efeito de regulador de crescimento etiltrinexapac e diferentes densidades de semeadura no município de Selvíria (MS), durante dois anos consecutivos.

\section{MATERIAL E MÉTODOS}

O trabalho foi realizado nos anos agrícolas de 2010/11 e 2011/12 na Fazenda de Ensino, Pesquisa e Extensão (FEPE) da Universidade Estadual Paulista "Júlio de Mesquita Filho”, localizada em Selvíria-MS, situada a 51 '22' de longitude oeste e $20^{\circ} 22^{\prime}$ de latitude sul, com altitude de $335 \mathrm{~m}$. O solo do local é um Latossolo Vermelho, epieutrófico álico, textura argilosa (SANTOS et al., 2006). O clima da região é do tipo Aw segundo a classificação Köppen apresentando temperatura média anual de $25^{\circ} \mathrm{C}$, precipitação total anual de $1330 \mathrm{~mm}$ e umidade relativa média de 66\% conforme citado por Centurion (1982).

Valores diários de precipitação pluvial, temperatura do ar e umidade relativa registrados durante o período de condução do experimento de arroz de terras altas, nos anos agrícolas de 2010/11 e 2011/12 estão apresentados na Figura 1.

Antes da instalação do experimento, foram coletadas amostras de solo da área referente ao primeiro cultivo, na profundidade de 0,0 a $0,2 \mathrm{~m}$, e realizada a análise química, para fins de fertilidade do solo, de acordo com a metodologia proposta por Raij et al. (2001) a qual revelou os seguintes valores: $\mathrm{MO}, 21 \mathrm{~g} \mathrm{dm}^{-3}$; $\mathrm{P}$ (resina), $35 \mathrm{mg} \mathrm{dm}^{-3} ; \mathrm{pH}\left(\mathrm{CaCl}_{2}\right), 5,5$; $\mathrm{K}, \mathrm{Ca}, \mathrm{Mg}$ e $\mathrm{H}+\mathrm{Al}, 1,7,21,11$ e $20 \mathrm{mmol}_{\mathrm{c}} \mathrm{dm}^{-3}$, respectivamente e $\mathrm{V} \%=63 \%$.

O delineamento experimental utilizado foi o de blocos ao acaso, no esquema de parcelas subdivididas com quatro repetições. Os tratamentos consistiram na combinação de nove densidades de semeadura $(60,90,120,150,180,210,240,270$ e 300 sementes viáveis

$\mathrm{m}^{-2}$ ) com e sem a aplicação do regulador vegetal etil-trinexapac na dose de $150 \mathrm{~g}$ do i.a. ha ${ }^{-1}$ por ocasião da diferenciação floral (NASCIMENTO, 2008). As subparcelas foram compostas de seis linhas de arroz de 4,5 m de comprimento espaçadas 0,35 m entre si e a 
área útil constitui-se de duas linhas centrais. Para o preparo do solo, foi realizada em ambos os anos uma escarificação e duas gradagens niveladoras; sendo uma, logo após a escarificação e a outra às vésperas da semeadura.
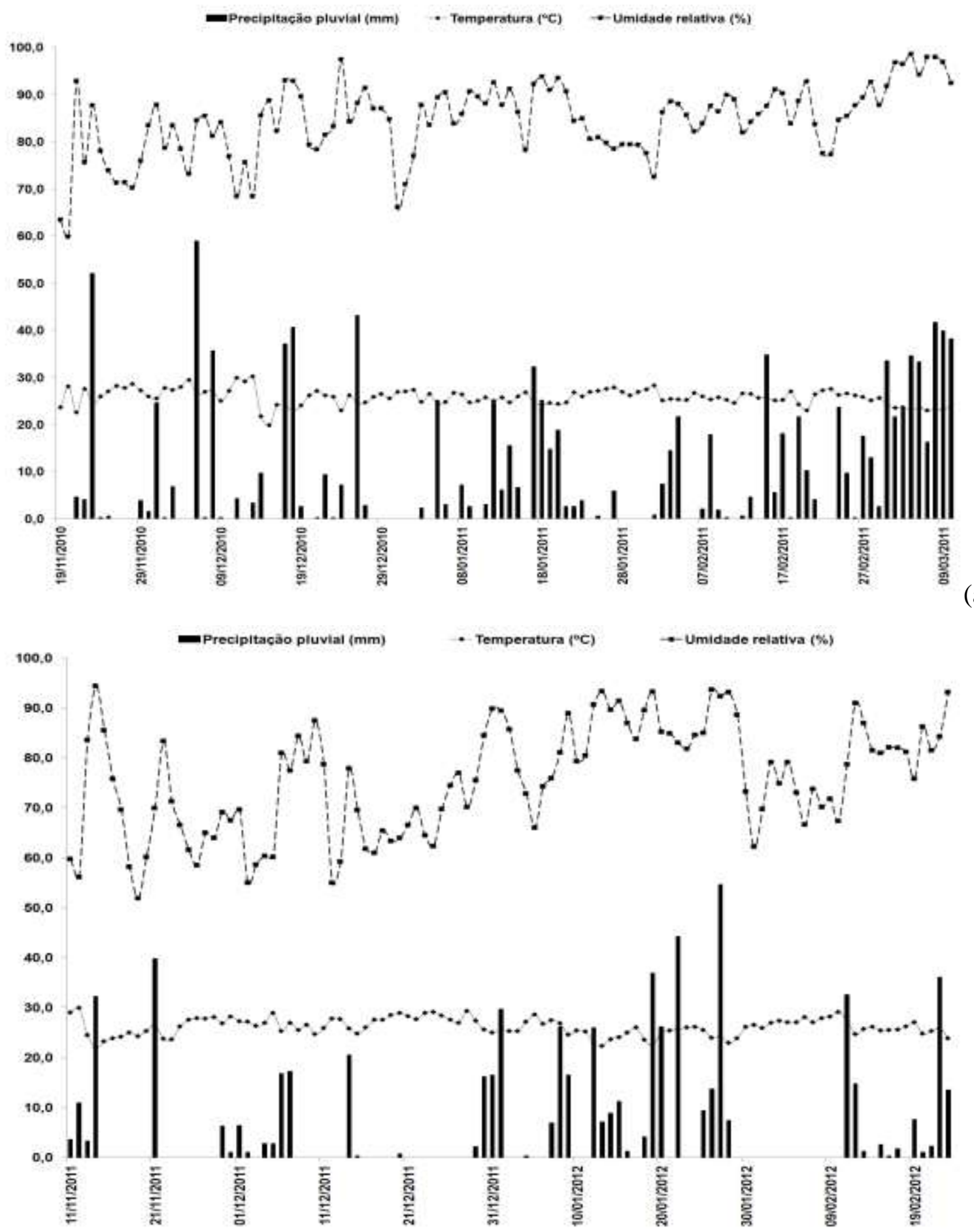

Figura 1. Valores diários de precipitação pluvial, temperatura do ar e umidade relativa registrados durante o período de condução do experimento de arroz de terras altas, no ano agrícola de 2010/11 (a) e 2011/12 (b).

Fonte: Elaborado pelo autor. Valores fornecidos pela Estação Agrometeorológica da FEPE, Selvíria-MS.

Cultura Agronômica, Ilha Solteira, v.24, n.2, p.119-134, 2015 
$\mathrm{Na}$ área experimental referente ao primeiro cultivo (2010/11) foi conduzida a cultura do arroz em 2009/10 e no que se refere a área do segundo ano (2011/12) esta foi cultivada com soja em 2010/11. O arroz foi semeado manualmente nos dias 19/11/2010 e 11/11/2011, utilizando-se o cultivar BRS Primavera e espaçamento de 0,35 m. Para a adubação de semeadura e de cobertura utilizaram-se as recomendações de Cantarella e Furlani (1997). Foram depositados nos sulcos $180 \mathrm{~kg} \mathrm{ha}^{-1}$ do formulado 08-28-16 (N-P $\left.\mathrm{O}_{5}-\mathrm{K}_{2} \mathrm{O}\right)+1 \% \mathrm{Zn}+$ $3 \% \mathrm{Ca}+0,3 \% \mathrm{~S}$ em 2010/11 e $250 \mathrm{~kg} \mathrm{ha}^{-1}$ de $04-30-10+0,3 \% \mathrm{Zn}$ em 2011/12. No que se refere à adubação nitrogenada em cobertura, para ambas as safras, utilizou-se a dose de 70 $\mathrm{kg} \mathrm{ha}^{-1}$ de nitrogênio e a fonte utilizada foi a uréia $(45 \%$ de $\mathrm{N})$. Juntamente com o fertilizante e as sementes, para controle de insetos de solo como a lagarta elasmo e cupins aplicou-se nos sulcos de semeadura $1000 \mathrm{~g} \mathrm{ha}^{-1}$ de carbofuran e em seguida cobriu-se as sementes com uma camada de 0,04 - 0,05 m de solo. $\mathrm{O}$ fertilizante foi depositado ao lado das plantas quando estas encontravam-se no perfilhamento ativo em seguida aplicou-se uma lâmina de água de aproximadamente $6 \mathrm{~mm}$.

No primeiro ano, para controle das plantas daninhas em pré-emergência, logo após a cobertura dos sulcos aplicou-se $1250 \mathrm{~g} \mathrm{ha}^{-1}$ do i.a. de pendimetalin. Em virtude do aparecimento de plantas daninhas em pós-emergência, aplicou-se $720 \mathrm{~g} \mathrm{ha}^{-1}$ do i.a. de bentazon quando as plantas de arroz estavam no início do perfilhamento. No segundo ano o controle em pós-emergência foi realizado mediante a aplicação de $2,4 \mathrm{~g} \mathrm{ha}^{-1}$ do i.a. de metsulfurom-metílico (início do perfilhamento) e $1,0 \mathrm{~g}$ do i.a. do ácido 2,4diclorofenóxiacético $(2,4-\mathrm{D})$ no período entre o fim do perfilhamento e o início do emborrachamento.

O regulador de crescimento etil-trinexapac foi aplicado nas subparcelas utilizando-se um pulverizador costal de pressão constante de $\mathrm{CO}_{2}$ aos 38 e 40 DAE para a primeira e segunda safra respectivamente. A área foi irrigada com sistema fixo de irrigação convencional por aspersão com vazão de $3,3 \mathrm{~mm} \mathrm{~h}^{-1}$ nos aspersores. No manejo de água foram utilizados três coeficientes de cultura (Kc), distribuídos em quatro períodos compreendidos entre a emergência e a colheita. Para a fase vegetativa foi utilizado o valor de 0,4; para a fase reprodutiva foram dois valores de Kc, o inicial de 0,7 e o final de 1,0 e para a fase de maturação estes valores foram invertidos, ou seja, o inicial de 1,0 e o final de 0,7 (RODRIGUES et al., 2004).

Quando aproximadamente $90 \%$ das panículas apresentavam grãos com coloração típica de maduros, realizou-se a colheita das linhas centrais, manualmente. Em seguida, as plantas foram trilhadas e os grãos foram espalhados em bandejas de jornal e mantidos em local seco e ventilado. No presente estudo foram realizadas as seguintes avaliações: grau de acamamento, obtido pela avaliação visual na fase de maturação dos grãos, utilizando-se a seguinte escala de notas: 0 - sem acamamento; 1 - até $5 \%$ de plantas acamadas; 2 - de 5 a $25 \%, 3$ - de 25 a 50\%; 4 - de 50 a $75 \%$ e 5 - de 75 a 100\% de plantas acamadas; altura de plantas, no estádio de maturação dos grãos, em cinco plantas ao acaso por parcela, utilizando-se uma régua milimetrada, tomou-se como referência a distância $(\mathrm{cm})$ compreendida entre a superfície do solo e a extremidade superior da panícula mais alta; massa hectolítrica, determinada pela pesagem de $0,25 \mathrm{~L}$ de arroz em casca corrigindo-se a

Cultura Agronômica, Ilha Solteira, v.24, n.2, p.119-134, 2015 
umidade para $13 \%$ (base úmida) com os resultados expressos em $\mathrm{kg} 100 \mathrm{~L}^{-1}$; número de espiguetas granadas, chochas e total por panícula, avaliadas pela contagem eletrônica do número médio de espiguetas em vinte panículas por subparcela; fertilidade de espiguetas, avaliada por meio da relação porcentual entre o número de espiguetas granadas e o número total de espiguetas por panícula; massa de 100 grãos, onde foram pesadas duas subamostras de 100 grãos de cada subparcela os quais tiveram sua umidade convertida para 13\% (base úmida); produtividade de grãos em casca, os grãos oriundos das duas linhas centrais de cada subparcela foram pesados e tiveram sua umidade corrigida para 13\% (base úmida) com os valores convertidos posteriormente para $\mathrm{kg} \mathrm{ha}^{-1}$.

Para a análise estatística dos resultados obtidos, utilizou-se o software ESTAT, para níveis de 1 e $5 \%$ de probabilidade. Quando verificado efeito significativo de densidades ou interação significativa entre regulador e densidades de semeadura foram realizadas análises de regressão e a comparação das médias entre uso ou não regulador de crescimento foi feita pelo teste de Tukey.

\section{RESULTADOS E DISCUSSÃO}

Os valores de altura de plantas, acamamento e espiguetas cheias do arroz em função do uso ou não de regulador de crescimento e densidades de semeadura nas safras 2010/11 e 2011/12, estão apresentados na Tabela 1 .

Quanto à altura de plantas, verificou-se que houve interação significativa entre densidades de semeadura e regulador de crescimento na safra 2010/11 cujo desdobramento da interação significativa encontra-se na Tabela 2. Observou-se que o uso do regulador reduziu a altura de plantas a partir da densidade de 120 sementes $\mathrm{m}^{-2}$. No que se refere à densidades dentro de regulador, obteve-se ajuste linear decrescente tanto na ausência quanto na presença do etil-trinexapac. Em 2011/12 obteve-se efeito do etil-trinexapac e das densidades. A aplicação do regulador reduziu a altura de plantas em 0,14 m. Para o efeito de densidades, observou-se que os dados ajustaram-se de maneira linear e decrescente. De modo geral, a redução da altura de plantas pode estar associada ao fato de que os reguladores atuam no metabolismo de giberelinas, hormônios que entre outras ações promovem o alongamento celular (DAVIES, 1995; TAIZ e ZEIGER, 2009). A redução da altura de plantas em função das densidades pode estar relacionada à competição intraespecífica que reduziu a quantidade de água, luz e nutrientes por planta diminuindo com isso a taxa fotossintética e a altura das plantas. $\mathrm{O}$ efeito decrescente das densidades de semeadura para esta variável também foi observado por Yamashita (2013) em trabalho com o cultivar BRS Primavera. 
Tabela 1. Altura de plantas, acamamento e espiguetas cheias por panícula (ECP) do arroz cv. Primavera em função de regulador de crescimento (RC) e densidade de semeadura (DS). Safra 2010/11 e 2011/12, Selvíria, MS $^{(1)}$.

\begin{tabular}{|c|c|c|c|c|c|c|c|}
\hline \multirow{2}{*}{\multicolumn{2}{|c|}{ Tratamentos }} & \multicolumn{2}{|c|}{ Altura de plantas $(\mathrm{cm})$} & \multicolumn{2}{|c|}{ Acamamento $^{(3)}$} & \multicolumn{2}{|c|}{$\operatorname{ECP}\left(n^{\circ}\right.$ panícula $\left.^{-1}\right)$} \\
\hline & & $2010 / 11$ & $2011 / 12$ & $2010 / 11$ & $2011 / 12$ & $2010 / 11$ & $2011 / 12$ \\
\hline \multirow{2}{*}{$\mathrm{RC}$} & $\mathrm{CR}$ & 80,4 & $109,1 \mathrm{~b}$ & 0,71 & 0,71 & $101,6 \mathrm{~b}$ & 104,5 \\
\hline & SR & 89,3 & $123,1 \mathrm{a}$ & 0,71 & 2,06 & $126,3 \mathrm{a}$ & 92,5 \\
\hline \multirow{9}{*}{ DS } & 60 & 92,3 & $120,1^{(2)}$ & 0,71 & 1,25 & 127,1 & 101,2 \\
\hline & 90 & 90,4 & 118,9 & 0,71 & 1,32 & 109,1 & 110,8 \\
\hline & 120 & 86,7 & 121,6 & 0,71 & 1,40 & 130,6 & 95,8 \\
\hline & 150 & 87,7 & 119,6 & 0,71 & 1,28 & 121,7 & 106,1 \\
\hline & 180 & 83,2 & 111,2 & 0,71 & 1,41 & 116,4 & 105,5 \\
\hline & 210 & 82,6 & 114,2 & 0,71 & 1,43 & 108,8 & 78,2 \\
\hline & 240 & 81,9 & 112,4 & 0,71 & 1,34 & 101,8 & 105,1 \\
\hline & 270 & 80,2 & 115,1 & 0,71 & 1,49 & 105,4 & 90,2 \\
\hline & 300 & 79,0 & 114,6 & 0,71 & 1,51 & 104,9 & 93,4 \\
\hline \multirow{3}{*}{$\begin{array}{c}\text { Teste } \\
\text { F }\end{array}$} & $\mathrm{RC}$ & $70,94 * *$ & $80,73 * *$ & - & $87,78 * *$ & $33,27 * *$ & $9,76^{\mathrm{ns}}$ \\
\hline & DS & $8,08 *$ & $2,96 * *$ & - & $3,55^{* *}$ & $1,56^{\mathrm{ns}}$ & $8,82 * *$ \\
\hline & $\mathrm{RC} \times \mathrm{DS}$ & $2,49 *$ & $1,78^{\mathrm{ns}}$ & - & $3,85^{* *}$ & $1,30^{\mathrm{ns}}$ & $5,60 * *$ \\
\hline \multicolumn{2}{|c|}{ CV.1 (\%) } & 5,27 & 5,67 & - & 7,22 & 15,91 & 16,47 \\
\hline \multicolumn{2}{|c|}{ CV.2(\%) } & 5,41 & 7,32 & - & 9,54 & 20,74 & 9,80 \\
\hline
\end{tabular}

${ }^{(1)}$ Médias seguidas de mesma letra na coluna, não diferem entre si, ao nível de $5 \%$, pelo teste de Tukey. ${ }^{\text {ns }}$ - não significativo. ${ }^{*}$ e* significativo a 5 e $1 \%$ de probabilidade respectivamente. ${ }^{(2)} \mathrm{Y}=122,58-0,0318 \mathrm{x} ; \mathrm{R}^{2}=$ 0,66. CR - Com regulador. SR - Sem regulador. ${ }^{(3)}$ Dados transformados em $\sqrt{ } \mathrm{x}+0,5$. Notas de acamamento: 0 - sem acamamento; 1 - até 5\% de plantas acamadas; 2 - de 5 a $25 \%, 3$ - de 25 a $50 \%$; 4 - de 50 a $75 \%$ e 5 de 75 a 100\%. CV. $1(\%)$ - Coeficiente de variação para parcela. CV. $2(\%)$ - Coeficiente de variação para subparcela.

Tabela 2. Desdobramento da interação significativa referente à análise de variância para altura de plantas de arroz cv. Primavera em função de regulador de crescimento (RC) e densidade de semeadura (DS). Safra 2010/11 e 2011/12, Selvíria, MS ${ }^{(1)}$.

\begin{tabular}{cccccccccc}
\hline Tratamentos & 60 & 90 & 120 & 150 & 180 & 210 & 240 & 270 & 300 \\
\hline $\mathrm{CR}^{(2)}$ & $92,1 \mathrm{a}$ & $90,0 \mathrm{a}$ & $81,7 \mathrm{~b}$ & $82,9 \mathrm{~b}$ & $79,5 \mathrm{~b}$ & $75,7 \mathrm{~b}$ & $75,7 \mathrm{~b}$ & $74,3 \mathrm{~b}$ & $72,0 \mathrm{~b}$ \\
$\mathrm{SR}^{(3)}$ & $92,6 \mathrm{a}$ & $90,7 \mathrm{a}$ & $91,8 \mathrm{a}$ & $92,4 \mathrm{a}$ & $86,9 \mathrm{a}$ & $89,5 \mathrm{a}$ & $88,1 \mathrm{a}$ & $86,0 \mathrm{a}$ & $85,9 \mathrm{a}$ \\
\hline
\end{tabular}

${ }^{(1)}$ Médias seguidas de mesma letra na coluna, não diferem entre si, ao nível de $5 \%$, pelo teste de Tukey. ${ }^{(2)} \mathrm{Y}=$ $95,11-0,0815 x ; R^{2}=0,92 .{ }^{(3)} Y=94,44-0,0284 x ; R^{2}=0,75$. Notas de acamamento: 0 - sem acamamento; 1 - até $5 \%$ de plantas acamadas; 2 - de 5 a $25 \%, 3$ - de 25 a $50 \% ; 4$ - de 50 a $75 \%$ e 5 - de 75 a $100 \%$. CR Com regulador. SR - Sem regulador.

Verificou-se que na primeira safra não houve acamamento de plantas. Na segunda, houve efeito para regulador de crescimento, densidades de semeadura e da interação. O desdobramento da interação significativa encontra-se na Tabela 3. Para densidades em regulador houve ajuste linear positivo para o tratamento sem aplicação. Quanto ao efeito de regulador em densidades, observou-se que este reduziu o acamamento em todas as populações testadas. O acamamento de plantas não foi observado no ano de 2010/11, contudo, no ano seguinte, o etil-trinexapac reduziu o porcentual de plantas acamadas em 
todas as densidades de semeadura. Com relação ao efeito de densidades em regulador, obteve-se ajuste linear crescente no tratamento sem aplicação (Tabela 3). O comportamento distinto referente ao regulador em ambos os anos está relacionado ao histórico do local, visto que, na segunda safra o arroz foi semeado em local anteriormente cultivado com soja, portanto, é provável que no local havia maior disponibilidade de nitrogênio no solo o que favoreceu o crescimento vegetativo das plantas na ausência do regulador. Nascimento et al. (2009) e Castilho et al. (2012) verificaram que a aplicação de $150 \mathrm{~g} \mathrm{ha}^{-1}$ de etil-trinexapac no momento da diferenciação floral do arroz cultivar BRS Primavera reduziu o acamamento e atribuíram o fato à redução na altura de plantas.

Tabela 3. Desdobramento da interação significativa referente ao acamamento de plantas de arroz cv. Primavera em função de regulador de crescimento (RC) e densidade de semeadura (DS). Safra 2010/11 e 2011/12, Selvíria, $\mathrm{MS}^{(1)}$.

\begin{tabular}{cccccccccc}
\hline Tratamentos & 60 & 90 & 120 & 150 & 180 & 210 & 240 & 270 & 300 \\
\hline $\mathrm{CR}^{(\mathrm{ns})}$ & $0,71 \mathrm{~b}$ & $0,71 \mathrm{~b}$ & $0,71 \mathrm{~b}$ & $0,71 \mathrm{~b}$ & $0,71 \mathrm{~b}$ & $0,71 \mathrm{~b}$ & $0,71 \mathrm{~b}$ & $0,71 \mathrm{~b}$ & $0,71 \mathrm{~b}$ \\
$\mathrm{SR}^{(2)}$ & $1,79 \mathrm{a}$ & $1,93 \mathrm{a}$ & $2,09 \mathrm{a}$ & $1,87 \mathrm{a}$ & $2,12 \mathrm{a}$ & $2,17 \mathrm{a}$ & $1,98 \mathrm{a}$ & $2,28 \mathrm{a}$ & $2,30 \mathrm{a}$ \\
\hline
\end{tabular}

${ }^{(1)}$ Médias seguidas de mesma letra na coluna, não diferem entre si, ao nível de 5\%, pelo teste de Tukey. ${ }^{(2)} \mathrm{Y}=$ $1,74+0,002 x ; R^{2}=0,66$. $C R-C o m$ regulador. $S R-S e m$ regulador.

Tabela 4. Desdobramento da interação significativa referente à análise de variância para número de espiguetas cheias por panícula do arroz cv. Primavera em função de regulador de crescimento (RC) e densidade de semeadura (DS). Safra 2010/11 e 2011/12, Selvíria, MS ${ }^{(1)}$.

\begin{tabular}{cccccccccc}
\hline Tratamentos & 60 & 90 & 120 & 150 & 180 & 210 & 240 & 270 & 300 \\
\hline $\mathrm{CR}^{(\mathrm{ns})}$ & $92,0 \mathrm{~b}$ & $124,7 \mathrm{a}$ & $100,7 \mathrm{a}$ & $121,2 \mathrm{a}$ & $114,0 \mathrm{a}$ & $82,0 \mathrm{a}$ & $100,0 \mathrm{a}$ & $88,0 \mathrm{~b}$ & $107,5 \mathrm{a}$ \\
$\mathrm{SR}^{(\mathrm{ns})}$ & $110,2 \mathrm{a}$ & $97,0 \mathrm{~b}$ & $91,0 \mathrm{~b}$ & $91,0 \mathrm{~b}$ & $97,0 \mathrm{~b}$ & $74,5 \mathrm{a}$ & $100,2 \mathrm{a}$ & $92,5 \mathrm{a}$ & $79,2 \mathrm{~b}$ \\
\hline
\end{tabular}

${ }^{(1)}$ Médias seguidas de mesma letra na coluna, não diferem entre si, ao nível de 5\%, pelo teste de Tukey. ${ }^{\text {ns }}$ não significativo. $\mathrm{CR}$ - Com regulador. SR - Sem regulador.

Com relação ao número de espiguetas cheias por panícula houve efeito significativo para o regulador de crescimento na safra 2010/11. O uso do etil-trinexapac reduziu o número de espiguetas cheias em 19\%. Em 2011/12, observou-se efeito de densidade e da interação regulador $\mathrm{x}$ densidade (Tabela 4). $\mathrm{O}$ uso do regulador teve efeito negativo neste componente de produtividade nas densidades de 60 e 270 sementes $\mathrm{m}^{-2}$ e não houve ajuste significativo em função de densidades. Na segunda safra este comportamento foi distinto, em tal situação, o efeito do etil-trinexapac foi observado em valores extremos de densidade de semeadura. Este resultado indica que o regulador pode ter influenciado o processo de fecundação de flores o que diminui o número de espiguetas cheias por panícula. Conforme Alvarez et al. (2007), a aplicação de $200 \mathrm{~g} \mathrm{~L}^{-1}$ de etil-trinexapac reduziu o número de espiguetas cheias por panícula.

Os valores médios de espiguetas chochas por panícula, panículas por metro quadrado e número de espiguetas por panícula da cultura do arroz em função do uso ou não de regulador de crescimento e densidades de semeadura nos anos agrícolas 2010/11 e 2011/12 estão na Tabela 5. 
Tabela 5. Valores médios de espiguetas chochas, panículas por metro quadrado e número total de espiguetas por panícula do arroz cv. Primavera em função de regulador de crescimento (RC) e densidade de semeadura (DS). Safra 2010/11 e 2011/12, Selvíria, MS ${ }^{(1)}$.

\begin{tabular}{|c|c|c|c|c|c|c|c|}
\hline \multicolumn{2}{|c|}{ Tratamentos } & \multicolumn{2}{|c|}{$\begin{array}{l}\text { Espiguetas chochas } \\
\quad\left(\mathrm{n}^{\mathbf{o}} \text { panícula }^{-1}\right)\end{array}$} & \multicolumn{2}{|c|}{ Panículas $\mathrm{m}^{-2}$} & \multicolumn{2}{|c|}{$\begin{array}{l}\text { Total de espiguetas } \\
\left(\mathrm{n}^{\circ} \text { panícula }^{-1}\right)\end{array}$} \\
\hline & & $2010 / 11$ & $2011 / 12$ & $2010 / 11$ & $2011 / 12$ & $2010 / 11$ & $2011 / 12$ \\
\hline \multirow{2}{*}{$\mathrm{RC}$} & CR & 10,2 & $24,9 \mathrm{~b}$ & $207 \mathrm{a}$ & 456 & $111,9 \mathrm{~b}$ & 129,5 \\
\hline & SR & 14,3 & $37,3 \mathrm{a}$ & $197 \mathrm{~b}$ & 450 & 140,6 a & 129,7 \\
\hline \multirow{9}{*}{ DS } & 60 & 13,6 & $39,1^{(2)}$ & $193^{(3)}$ & 444 & 140,7 & 140,2 \\
\hline & 90 & 11,6 & 30,2 & 196 & 437 & 120,7 & 141,1 \\
\hline & 120 & 12,8 & 27,8 & 201 & 437 & 143,5 & 123,7 \\
\hline & 150 & 14,5 & 36,6 & 210 & 480 & 136,2 & 142,7 \\
\hline & 180 & 12,0 & 33,5 & 223 & 431 & 128,4 & 139,2 \\
\hline & 210 & 13,0 & 34,6 & 204 & 445 & 121,8 & 112,8 \\
\hline & 240 & 10,4 & 25,5 & 198 & 479 & 112,5 & 130,6 \\
\hline & 270 & 10,6 & 28,4 & 190 & 454 & 116,0 & 118,6 \\
\hline & 300 & 11,9 & 24,2 & 188 & 470 & 116,7 & 117,2 \\
\hline \multirow{3}{*}{ Teste F } & $\mathrm{RC}$ & $21,45^{* *}$ & $44,38 * *$ & $151,94 * *$ & $6,57 * *$ & $33,62 * *$ & $0,12^{\mathrm{ns}}$ \\
\hline & DS & $2,48^{*}$ & $3,15^{* *}$ & $75,86 * *$ & $0,35^{*}$ & $1,90^{\mathrm{ns}}$ & $6,44 * *$ \\
\hline & $\mathrm{RC} \times \mathrm{DS}$ & $3,66 * *$ & $0,79^{\mathrm{ns}}$ & $1,03^{\mathrm{ns}}$ & $2,58 *$ & $1,29^{\mathrm{ns}}$ & $3,69 * *$ \\
\hline \multicolumn{2}{|c|}{ CV.1 (\%) } & 30,68 & 25,18 & 2,46 & 10,30 & 16,64 & 10,58 \\
\hline \multicolumn{2}{|c|}{ CV.2(\%) } & 19,81 & 26,22 & 16,61 & 12,23 & 18,59 & 10,08 \\
\hline
\end{tabular}

${ }^{(1)}$ Médias seguidas de mesma letra na coluna, não diferem entre si, ao nível de $5 \%$, pelo teste de Tukey. ${ }^{\text {ns }}$ - não significativo. *e **significativo a 5 e $1 \%$ de probabilidade respectivamente. ${ }^{(2)} \mathrm{Y}=34,42+0,014 \mathrm{x}-0,0001 \mathrm{x}^{2}$; $\mathrm{R}^{2}=0,43\left(\mathrm{PM}=70\right.$ sementes $\left.\mathrm{m}^{-2}\right) \cdot{ }^{(3)} \mathrm{Y}=163,43+0,5437 \mathrm{x}-0,0016 \mathrm{x}^{2}\left(\mathrm{PM}=170\right.$ sementes $\left.\mathrm{m}^{-2}\right) ; \mathrm{R}^{2}=0,69$. CR - Com regulador. SR - Sem regulador. CV. $1(\%)$ - Coeficiente de variação para parcela. CV. 2 (\%) Coeficiente de variação para subparcela.

Tabela 6. Desdobramento da interação significativa referente à análise de variância para número de espiguetas chochas por panícula do arroz cv. Primavera em função de regulador de crescimento (RC) e densidade de semeadura (DS). Safra 2010/11 e 2011/12, Selvíria, $\mathrm{MS}^{(1)}$.

\begin{tabular}{cccccccccc}
\hline Tratamentos & 60 & 90 & 120 & 150 & 180 & 210 & 240 & 270 & 300 \\
\hline $\mathrm{CR}\left({ }^{\mathrm{ns}}\right)$ & $12,5 \mathrm{a}$ & $5,7 \mathrm{~b}$ & $11,7 \mathrm{a}$ & $13,0 \mathrm{a}$ & $11,5 \mathrm{a}$ & $9,7 \mathrm{~b}$ & $8,0 \mathrm{~b}$ & $9,0 \mathrm{a}$ & $10,7 \mathrm{a}$ \\
$\mathrm{SR}^{(2)}$ & $14,7 \mathrm{a}$ & $16,5 \mathrm{a}$ & $14,0 \mathrm{a}$ & $16,0 \mathrm{a}$ & $13,5 \mathrm{a}$ & $14,2 \mathrm{a}$ & $12,7 \mathrm{a}$ & $12,2 \mathrm{a}$ & $13,0 \mathrm{a}$ \\
\hline
\end{tabular}

${ }^{(1)}$ Médias seguidas de mesma letra na coluna, não diferem entre si, ao nível de $5 \%$, pelo teste de Tukey. ${ }^{\text {ns }}$ não significativo. ${ }^{(2)} \mathrm{Y}=16,49-0,0134 \mathrm{x} ; \mathrm{R}^{2}=0,57 . \mathrm{CR}-\mathrm{Com}$ regulador. $\mathrm{SR}-$ Sem regulador.

Para o número de espiguetas chochas por panícula verificou-se efeito significativo do regulador de crescimento, das densidades de semeadura e da interação regulador $\mathrm{x}$ densidades. No desdobramento (Tabela 6) constatou-se que a ausência do etil-trinexapac proporcionou maior número de espiguetas chochas nas densidades de 90, 210 e 240 sementes $\mathrm{m}^{-2}$ e houve efeito linear decrescente das densidades na ausência do regulador. Na segunda safra o uso do regulador reduziu o número de espiguetas chochas por panícula em $33,2 \%$. Quanto às densidades, verificou-se que os resultados ajustaram-se significativamente com ponto de máximo em 70 sementes $\mathrm{m}^{-2}$. Resultados semelhantes 
foram obtidos por Nascimento (2008) em trabalho com o cultivar Primavera utilizando a mesma dose e época de aplicação. Dario et al. (2004) avaliando o efeito do fitorregulador Stimulate $^{\circledR}$, em diferentes doses e modos de aplicação, no cultivar de arroz IAC 103, verificaram que os tratamentos não foram eficientes para a redução do porcentual de espiguetas chochas, diferentemente do obtido no presente experimento. Com relação ao efeito de densidades nesta variável é possível que o aumento da população de plantas por área resultou em condições mais desfavoráveis ao crescimento das plantas o que reduziu a quantidade de nutrientes e água absorvidos por planta, fato que foi observado em 2010/11. Na segunda safra, o máximo valor para este componente de produção foi obtido com uma densidade de semeadura baixa e, portanto, em condições de baixo estande o uso de etiltrinexapac não é favorável, pois desfavorece o enchimento dos grãos.

No que se refere ao número de panículas por metro quadrado, verificou-se efeito significativo para regulador e densidades na primeira safra (Tabela 5). O etil-trinexapac aumentou o número de panículas por metro quadrado em relação à testemunha sem aplicação, possivelmente houve uma realocação de assimilados produzidos que seriam utilizados para o crescimento vegetativo para a produção de mais panículas. Para densidades, verificou-se que os resultados ajustaram-se de maneira quadrática com ponto de máximo em 170 sementes $\mathrm{m}^{-2}$. Este comportamento indica que a partir desta densidade ocorreu uma redução da produção do número de estruturas reprodutivas pela competição intraespecífica o que reduziu o perfilhamento útil das plantas. Na safra seguinte observou-se pelo desdobramento que o etil-trinexapac reduziu o número de panículas $\mathrm{m}^{-2}$ na maior densidade e não obteve-se ajuste matemático em função das densidades (Tabela 7).

Tabela 7. Desdobramento da interação significativa referente à análise de variância para panículas $\mathrm{m}^{-2}$ do arroz cv. Primavera em função de regulador de crescimento (RC) e densidade de semeadura (DS). Safra 2010/11 e 2011/12, Selvíria, MS ${ }^{(1)}$.

\begin{tabular}{cccccccccc}
\hline Tratamentos & 60 & 90 & 120 & 150 & 180 & 210 & 240 & 270 & 300 \\
\hline $\mathrm{CR}^{(\mathrm{ns})}$ & $441 \mathrm{a}$ & $466 \mathrm{a}$ & $453 \mathrm{a}$ & $495 \mathrm{a}$ & $467 \mathrm{a}$ & $443 \mathrm{a}$ & $504 \mathrm{a}$ & $432 \mathrm{a}$ & $405 \mathrm{~b}$ \\
$\mathrm{SR}^{(\mathrm{ns})}$ & $447 \mathrm{a}$ & $407 \mathrm{a}$ & $421 \mathrm{a}$ & $466 \mathrm{a}$ & $395 \mathrm{a}$ & $447 \mathrm{a}$ & $454 \mathrm{a}$ & $476 \mathrm{a}$ & $534 \mathrm{a}$ \\
\hline
\end{tabular}

${ }^{(1)}$ Médias seguidas de mesma letra na coluna, não diferem entre si, ao nível de 5\%, pelo teste de Tukey. ${ }^{\text {ns }}$ não significativo. $\mathrm{CR}$ - Com regulador. SR - Sem regulador.

Para o número de espiguetas por ánícula houve efeito para regulador de crescimento na primeira safra (Tabela 5). A aplicação de etil-trinexapac reduziu o número de espiguetas por panícula em 20,5\% em relação à testemunha. Na segunda safra, houve efeito significativo de densidades e da interação regulador $\mathrm{x}$ densidades. No desdobramento (Tabela 8), o uso de regulador reduziu o número de espiguetas por panícula quando utilizouse 60, 270 e 300 sementes $\mathrm{m}^{-2}$, possivelmente sua aplicação contribuiu de maneira negativa para formação de ramificações da ráquis e epiguetas por ramificações, reduzindo com isso o número de espiguetas por panícula. Para densidades em regulador os valores ajustaram-se de forma linear decrescente na ausência do regulador. Alvarez et al. (2007) em trabalho com a cultura do arroz, cv. Primavera verificaram que entre os reguladores de crescimento cloreto de mepiquat, paclobutrazol e etil-trinexapac, que este proporcionou o menos número de espiguetas por panícula.

Cultura Agronômica, Ilha Solteira, v.24, n.2, p.119-134, 2015 
Tabela 8. Desdobramento da interação significativa referente à análise de variância para número total de espiguetas por panícula do arroz cv. Primavera em função de regulador de crescimento (RC) e densidade de semeadura (DS). Safra 2010/11 e 2011/12, Selvíria, MS ${ }^{(1)}$.

\begin{tabular}{cccccccccc}
\hline Tratamentos & 60 & 90 & 120 & 150 & 180 & 210 & 240 & 270 & 300 \\
\hline $\mathrm{CR}^{(\mathrm{ns})}$ & $123,5 \mathrm{~b}$ & $145,5 \mathrm{a}$ & $125,0 \mathrm{a}$ & $149,7 \mathrm{a}$ & $144,2 \mathrm{a}$ & $108,0 \mathrm{a}$ & $131,0 \mathrm{a}$ & $109,2 \mathrm{~b}$ & $105,2 \mathrm{~b}$ \\
$\mathrm{SR}^{(2)}$ & $157,0 \mathrm{a}$ & $136,7 \mathrm{a}$ & $122,5 \mathrm{a}$ & $135,7 \mathrm{a}$ & $134,4 \mathrm{a}$ & $117,7 \mathrm{a}$ & $130,2 \mathrm{a}$ & $128,0 \mathrm{a}$ & $129,2 \mathrm{a}$ \\
\hline
\end{tabular}

${ }^{\left({ }^{1}\right)}$ Médias seguidas de mesma letra na coluna, não diferem entre si, ao nível de 5\%, pelo teste de Tukey. ${ }^{\text {ns }}$ não significativo. ${ }^{(2)} \mathrm{Y}=153,3-0,1311 \mathrm{x} ; \mathrm{R}^{2}=0,56 . \mathrm{CR}-\mathrm{Com}$ regulador. $\mathrm{SR}-\mathrm{Sem}$ regulador.

Os valores médios de massa de cem grãos, produtividade e massa hectolítrica em função do uso ou não do regulador de crescimento e densidades de semeadura nos anos agrícolas 2010/11 e 2011/12 encontram-se na Tabela 9.

Tabela 9. Os valores médios de massa de cem grãos, produtividade e massa hectolítrica de grãos de arroz cv. Primavera em função de regulador de crescimento (RC) e densidade de semeadura (DS). Safra 2010/11 e 2011/12, Selvíria, MS ${ }^{(1)}$.

\begin{tabular}{|c|c|c|c|c|c|c|c|}
\hline \multirow{2}{*}{\multicolumn{2}{|c|}{ Tratamentos }} & \multicolumn{2}{|c|}{ Massa de 100 grãos (g) } & \multicolumn{2}{|c|}{$\begin{array}{l}\text { Produtividade } \\
\left(\mathrm{kg} \mathrm{ha}^{-1}\right)\end{array}$} & \multicolumn{2}{|c|}{$\begin{array}{l}\text { Massa hectolítrica } \\
\quad\left(\mathrm{kg} 100 \mathrm{~L}^{-1}\right)\end{array}$} \\
\hline & & $2010 / 11$ & $2011 / 12$ & $2010 / 11$ & $2011 / 12$ & $2010 / 11$ & $2011 / 12$ \\
\hline \multirow{2}{*}{$\mathrm{RC}$} & $\mathrm{CR}$ & $2,33 \mathrm{a}$ & 2,56 & 3.027 & $5.061 \mathrm{a}$ & 45,7 & 52,7 \\
\hline & SR & $2,18 \mathrm{~b}$ & 2,40 & 2.993 & $3.721 \mathrm{~b}$ & 44,3 & 52,4 \\
\hline \multirow{9}{*}{ DS } & 60 & $2,08^{(2)}$ & 2,49 & 3.123 & $4.946^{(3)}$ & $41,5^{(4)}$ & $49,0^{(5)}$ \\
\hline & 90 & 2,07 & 2,46 & 2.980 & 4.618 & 41,7 & 49,6 \\
\hline & 120 & 2,26 & 2,50 & 3.155 & 5.027 & 44,2 & 51,7 \\
\hline & 150 & 2,22 & 2,62 & 3.231 & 4.178 & 44,3 & 52,5 \\
\hline & 180 & 2,27 & 2,32 & 3.099 & 4.388 & 45,5 & 53,4 \\
\hline & 210 & 2,33 & 2,51 & 2.750 & 3.753 & 46,9 & 54,9 \\
\hline & 240 & 2,38 & 2,52 & 2.901 & 3.981 & 47,5 & 55,3 \\
\hline & 270 & 2,38 & 2,56 & 3.100 & 4.265 & 46,7 & 52,9 \\
\hline & 300 & 2,33 & 2,38 & 2.749 & 4.063 & 46,7 & 53,5 \\
\hline \multirow{3}{*}{$\begin{array}{c}\text { Teste } \\
\text { F }\end{array}$} & $\mathrm{RC}$ & $19,43 * *$ & $8,39^{\text {ns }}$ & $0,08^{\text {ns }}$ & $46,17 * *$ & $1,14^{\mathrm{ns}}$ & $0,10^{\mathrm{ns}}$ \\
\hline & DS & $5,11 * *$ & $1,10^{\mathrm{ns}}$ & $0,79^{\mathrm{ns}}$ & $2,35^{*}$ & $7,68^{* *}$ & $3,32 * *$ \\
\hline & $\mathrm{RC} \times \mathrm{DS}$ & $0,42^{\mathrm{ns}}$ & $1,25^{\mathrm{ns}}$ & $0,28^{\mathrm{ns}}$ & $1,35^{\mathrm{ns}}$ & $0,78^{\mathrm{ns}}$ & $1,27^{\mathrm{ns}}$ \\
\hline \multicolumn{2}{|c|}{ CV.1 (\%) } & 6,33 & 9,31 & 16,30 & 19,04 & 12,26 & 7,53 \\
\hline \multicolumn{2}{|c|}{ CV.2(\%) } & 6,44 & 9,55 & 18,62 & 19,56 & 5,07 & 6,35 \\
\hline
\end{tabular}

${ }^{(1)}$ Médias seguidas de mesma letra na coluna, não diferem entre si, ao nível de 5\%, pelo teste de Tukey. ${ }^{\text {ns }}$ - não significativo. ${ }^{*}{ }^{* *}$ significativo a 5 e $1 \%$ de probabilidade respectivamente. ${ }^{(2)} \mathrm{Y}=2,0298+0,0013 \mathrm{x} ; \mathrm{R}^{2}=$ 0,79. ${ }^{(3)} \mathrm{Y}=5068,6-3,95 \mathrm{x} ; \mathrm{R}^{2}=0,56 .{ }^{(4)} \mathrm{Y}=37,148+0,0707 \mathrm{x}-0,0001 \mathrm{x}^{2} ; \mathrm{R}^{2}=0,94\left(\mathrm{PM}=353\right.$ sementes $\mathrm{m}^{-}$ $\left.{ }^{2}\right) .{ }^{(5)} \mathrm{Y}=43,631+0,0911 \mathrm{x}-0,0002 \mathrm{x}^{2} ; \mathrm{R}^{2}=0,89\left(\mathrm{PM}=228\right.$ sementes $\left.\mathrm{m}^{-2}\right) . \mathrm{CR}-$ Com regulador. $\mathrm{SR}-\mathrm{Sem}$ regulador. CV. $1(\%)$ - Coeficiente de variação para parcela. CV. $2(\%)$ - Coeficiente de variação para subparcela.

Para a massa de cem grãos, na primeira safra houve efeito significativo de regulador de crescimento e densidades de semeadura. $\mathrm{O}$ etil-trinexapac aumentou a massa de cem grãos em relação à testemunha o que conforme Nascimento et al. (2009) pode ser explicado pela redução da altura das plantas e redistribuição dos fotoassimilados que seriam destinados à elongação das plantas e que foram destinados ao enchimento das espiguetas.

Cultura Agronômica, Ilha Solteira, v.24, n.2, p.119-134, 2015 
No que se refere à densidades de semeadura, observou-se que houve ajuste linear positivo. Na segunda safra não houve efeito dos tratamentos utilizados.

Quanto à produtividade de grãos (Tabela 9) não houve efeito dos tratamentos utilizados na primeira safra. No segundo ano, obteve-se efeito de regulador de crescimento e de densidades de semeadura. A aplicação do regulador vegetal aumentou a produtividade de grãos em relação à testemunha. $\mathrm{O}$ comportamento distinto em ambos os anos pode ser explicado pelo histórico da área experimental, na segunda safra possivelmente havia uma maior quantidade de nitrogênio no solo proveniente da decomposição da soja oque favoreceria o acamamento de plantas, entretanto foi eliminado pelo regulador de crescimento. Já na primeira, o arroz foi cultivado pela terceira vez consecutiva no verão e, portanto as densidades proporcionaram uma produção de grãos por planta semelhante, não refletindo na produtividade do arroz em tal condição. Cazetta et al. (2008) verificaram que o guandu (Cajanus cajan) aumentou a produtividade do arroz, cv. IAC 202, irrigado por aspersão em sucessão na safra 2002/03 em relação às demais plantas de cobertura: milheto, sorgo granífero, milho, crotalária, mucuna-preta, além da vegetação espontânea no pousio.

Silva et al. (2009) observou resultados discrepantes ao deste trabalho em que o uso de etil-trinexapac na dose de $150 \mathrm{~g}$ do i.a. ha ${ }^{-1}$ aplicado na diferenciação floral reduziu a produtividade do cultivar Primavera. Buzetti et al. (2006) em pesquisa realizada na mesma região verificaram que a aplicação do regulador de crescimento cloreto de clormequat nas doses de 0,1 e $2 \mathrm{~L} \mathrm{ha}^{-1}$ aplicados no perfilhamento não tiveram influência sobre a produtividade dos cultivares IAC 201 e IAC 202. A inconsistência nestes trabalhos pode ser explicada pela capacidade de perfilhamento que cada cultivar possui o que proporciona aumento do número de panículas por metro quadrado e influencia o número de espiguetas cheias por panícula.

Para as densidades de semeadura obteve-se ajuste linear decrescente, indicando que a produtividade foi reduzida em função do aumento da densidade de semeadura. Este comportamento pode ser explicado pela competição intraespecífica entre as plantas de arroz na linha de semeadura o que reduziu a disponibilidade de fatores ambientais como luz, água, luminosidade e de nutrientes. A cultura do arroz apresenta uma adaptação dos seus componentes de produtividade às alterações do ambiente, com aumento da densidade de semeadura, é provável que este resultado esteja relacionado ao número de espiguetas por panícula (Tabela 8), visto que, este componente produtivo que possui estreita correlação com a produtividade por determinar a produção de grãos por planta também sofreu redução com o aumento da densidade de semeadura.

Quanto à massa hectolítrica houve efeito significativo das densidades de semeadura em ambas as safras. Observou-se que houve ajuste quadrático para ambas as safras com pontos de máximo em 353 e 228 sementes $\mathrm{m}^{-2}$. Este comportamento indica que no primeiro ano de estudo houve a necessidade de uma maior densidade de semeadura para obter a máxima massa hectolítrica, já na segunda safra, a densidade correspondente à máxima massa hectolítrica foi menor devido ao cultivo antecessor. Castilho et al. (2012) verificaram efeito somente para regulador sobre a massa hectolítrica em que o uso de etil-trinexapac 
aumentou o valor desta em comparação à testemunha sem aplicação.

\section{CONCLUSÃO}

O uso do regulador de crescimento etil-trinexapac reduz a altura e o acamamento das plantas.

O aumento da densidade de semeadura reduz a produtividade de grãos quando o arroz é cultivado em local que anteriormente fora cultivada leguminosas.

A produtividade do arroz é aumentada pelo uso do regulador devido à redução do número de espiguetas chochas, aumento da massa de cem grãos, redução do acamamento e da altura de plantas o que reduz as perdas de grãos na colheita.

\section{REFERÊNCIAS BIBLIOGRÁFICAS}

AlvareZ, R. C. F.; CRUSCIOL, C. A. C.; RODRIGUES, J. D.; ALVAREZ, A. C. C. Aplicação de reguladores vegetais na cultura de arroz de terras altas. Acta Scientiarum Agronomy, Maringá, v. 29, n. 2, p.241-249, 2007.

BIASI, A. L. Reguladores de crescimento vegetal. In: WACHOWICZ, C. M.; CARVALHO, R. I. N. (Org.). Fisiologia vegetal produção e pós-colheita. Curitiba: Champagnat, 2002. cap. 5, p. 63-94.

BUZETTI, S.; BAZANINI, G. C.; FREITAS, J. G.; ANDREOTTI, M.; ARF, O.; SÁ, M. E.; MEIRA, F. A. Resposta de cultivares de arroz a doses de nitrogênio e do regulador de crescimento cloreto de clormequat. Pesquisa Agropecuária Brasileira, Brasília, v. 41, n. 12, p.1731-1737, 2006.

CONAB - Companhia Nacional de Abastecimento. Acompanhamento da safra brasileira 2011/2012: grãos: décimo primeiro levantamento. Brasília, DF, 2012. Disponível em: <http://www.conab.gov.br/OlalaCMS/uploads/arquivos/12_08_27_09_50_57_boletim_port ugues_agosto_2012.pdf>. Acesso em: 15 ago. 2012.

CANTARELlA, H.; FURLANI, P. R. Arroz de sequeiro. In: RAIJ, B.; CANTARELlA, H.; GUAGGiO, J. A.; FURLANI, A. M. C. (Coords.). Recomendações de adubação e calagem para o Estado de São Paulo. 3. ed. Campinas: Instituto agronômico e Fundação IAC, 1997. cap. 13 , p. 48-49.

CARVALHO, J. A.; SOARES, A. A.; REIS, M. S. Efeito do espaçamento e densidade de semeadura sobre a produtividade e os componentes de produção da cultivar de arroz BRSMG CONAI. Ciência e Agrotecnologia, Lavras, v. 32, n. 3, p.785-791, 2008.

Cultura Agronômica, Ilha Solteira, v.24, n.2, p.119-134, 2015 
CASTILHO, J. S.; ARF, O.; GITTI, D. C.; KOGA, P. S. L.; RODRIGUES, R. A. F. Regulador vegetal e densidades de semeadura na cultura do arroz de terras altas. Agrarian, Dourados, v. 5, n. 18, p.337-348, 2012.

CAZETTA, D. A.; ARF, O.; BUZETTI, S.; SÁ, M. E.; RODRIGUES, R.A.F. Desempenho do arroz de terras altas com a aplicação de doses de nitrogênio e em sucessão às culturas de cobertura do solo em sistema de plantio direto. Bragantia, Campinas, v. 67, n. 2, p.471-479, 2008.

CENTURION, J. F. Balanço hídrico na região de Ilha Solteira. Científica, Jaboticabal, v. 10, n. 1, p.57-61, 1982.

CRUSCIOL, C. A. C.; SORATTO, R. P.; ARF, O. Produtividade de grãos e exportação de nutrientes de cultivares de arroz irrigado por aspersão em consequiência da época de semeadura. Bragantia, Campinas, v. 66, n. 2, p.247-257, 2007.

DARIO, G. J. A.; NETO, D. D.; MARTIN, T. N.; BONNECARRÉRE, R. A. G.; MANFRON, P. A.; FAGAN, E. B.; CRESPO, P. E. N. Influência do uso de fitorregulador no crescimento do arroz irrigado. Revista da FZVA, Uruguaiana, v. 11, n. 1, p.86-94. 2004.

DAVIES. P. J. Plant hormones physiology biochemistry and molecular biology. 2. ed. Netherlands: Klumer Academic Publishes, 1995. 823 p.

GUIMARÃES, C. M.; STONE, L. F. Arroz de terras altas em rotação com soja. Pesquisa Agropecuária Tropical, Goiânia, v. 34, n. 3, p.127-132, 2004.

HECKMAN, N. L.; ELTHON, T. E.; HORST, G. L.; GAUSSOIN, R. E. Influence of trinexapac-ethyl on respiration of isolated wheat mitochondria. Crop Science, Madison, v. 42, n. 2, p.423-427, 2002.

NASCIMENTO, V. Resposta do arroz a doses e épocas de aplicação do regulador de crescimento etil-trinexapac. 2008. 52 f. Dissertação (Mestrado em Agronomia - Sistemas de Produção) - Faculdade de Engenharia, Universidade Estadual Paulista "Júlio de Mesquita Filho", Ilha Solteira, 2008.

NASCIMENTO, V.; ARF, O.; SILVA, M. G.; BINOTTI, F. F. S.; RODRIGUES, R. A. F.; ALVAREZ, R. C. F. Uso do regulador de crescimento etil-trinexapac em arroz de terras altas. Bragantia, Campinas, v. 68, n. 4, p.921-929, 2009.

RAIJ, B. VAN; ANDRADE, J. C.; CANTARELlA, H.; QUAGGIO, J. A. Análise química para avaliação da fertilidade de solo tropicais. Campinas: IAC, 2001. 285 p. 
RODRIGUES, R. A. F.; SORATTO, R. P.; ARF, O. Manejo de água em arroz de terras altas no sistema de plantio direto, usando o tanque classe A. Engenharia Agrícola, Jaboticabal, v. 24, n. 3, p.546-556, 2004.

SANTOS, H. G.; JACOMINE, P. K. T.; ANJOS, L. H. C.; OLIVEIRA, V. A.; OLIVEIRA, J. B.; COELHO, M. R.; LUMBRERAS, J. F.; CUNHA, T. J. F. (Ed.). Sistema brasileiro de classificação de solos. 2. ed. Rio de Janeiro: Embrapa Solos, 2006. 306 p.

SILVA, M. R. R. Regulador de crescimento etil-trinexapac em diferentes densidades de semeadura na cultura do arroz de terras altas. 2009. $81 \mathrm{f}$. Tese (Doutorado em Agronomia - Sistemas de Produção) - Faculdade de Engenharia de Ilha Solteira, Universidade Estadual Paulista "Júlio de Mesquita Filho", Ilha Solteira, 2009.

SILVA, P. R. F.; SANGOI, L.; ARGENTA, G.; STRIEDER, M. L. Importância do arranjo de plantas na definição da produtividade do milho. Porto Alegre: UFRGS, 2006. $65 \mathrm{p}$.

SOARES, A. A. Cultura do arroz. 2.ed. Lavras: UFLA/FAEPE, 2005. 130 p.

TAIZ, L.; ZEIGER, E. Fisiologia vegetal. 3. ed. Porto Alegre: Artmed, 2009. 848 p.

YAMASHITA, A. S. T. Doses e épocas de aplicação de etil-trinexapac em arroz de terras altas irrigado por aspersão. 2013. 51 f. Dissertação (Mestrado em Agronomia Sistemas de Produção) - Faculdade de Engenharia de Ilha Solteira, Universidade Estadual Paulista "Júlio de Mesquita Filho", Ilha Solteira, 2013.

Cultura Agronômica, Ilha Solteira, v.24, n.2, p.119-134, 2015 
